\title{
Comunidades quilombolas: elementos conceituais para sua compreensão
}

\section{Wesley Santos de Matos ${ }^{1}$ e Benedito Gonçalves Eugenio ${ }^{2}$}

1 Mestre em Relações Étnicas e Contemporaneidade. Docente de História na educação básica. Brasil. E-mail: wesleyxdmattos@hotmail.com

2 Doutor em Educação (UNICAMP). Professor da Universidade Estadual do Sudoeste da Bahia. Programa de Pós-graduação em Ensino (PPGEn/UESB), Brasil. E-mail: beneditoeugenio@bol.com.br

RESUMO: Este trabalho apresenta uma sistematização introdutória acerca das principais discussões teóricas sobre as comunidades quilombolas. O texto, de caráter bibliográfico, pontua alguns elementos teórico-conceituais que nos auxiliam a compreender essas comunidades. O termo quilombola aparece pela primeira vez na Constituição de 1988. No âmbito dos debates políticos, abriu-se ampla discussão interpretativa acerca do seu teor semântico, uma vez que pairava sobre ele uma ambiguidade interpretativa. Apresentamos as duas perspectivas teóricas que se constituíram para explicar as questões relacionadas à definição das comunidades quilombolas. Neste artigo pontuamos alguns elementos teórico-conceituais que nos auxiliam a compreender os quilombolas, por nós compreendido como um grupo étnico. É um texto bibliográfico que pretende contribuir com a compreensão das atuais discussões acerca das comunidades quilombolas. Inicialmente abordamos o processo de produção da etnicidade. Na sequencia, apresentamos conceitos teóricos que nos permitem tomar os quilombolas enquanto grupo étnico.

Palavras-chaves: Comunidades quilombolas. Grupos étnicos. Quilombos.

\section{Quilombola communities: conceptual elements for their understanding}

ABSTRACT: This paper presents an introductory systematization about the main theoretical discussions about quilombola communities. The text, of bibliographic character, points out some theoretical-conceptual elements that help us to understand these communities. The term quilombola appears for the first time in the Constitution of 1988. In the context of the political debates, a wide interpretative discussion about its semantic content was opened, since an interpretative ambiguity loomed over it. We present the two theoretical perspectives that were constituted to explain the issues related to the definition of quilombola communities. In this article we point out some theoretical-conceptual elements that help us understand the quilombolas, understood by us as an ethnic group. It is a bibliographic text that intends to contribute with the understanding of the current discussions about the quilombola communities. We first approach the process of producing ethnicity. In the sequence, we present theoretical concepts that allow us to take the quilombolas as an ethnic group.

Keywords: Quilombola communities. Ethnic groups. Quilombos

\section{INTRODUÇÃO}

Segundo Arruti (2008, p.320), sempre falamos em quilombos adjetivando (rural ou ur- 
bano, contemporâneos/históricos), contudo, o que de fato está em jogo ao tratarmos do conceito contemporâneo de quilombo:

não é a existência destas formações sociais, nem mesmo das suas justas demandas, mas a maior ou menor largueza pela qual o conceito as abarcará, ou excluirá completamente. Está em jogo o quanto de realidade social o conceito será capaz de fazer reconhecer. Qual parcela da realidade ganhará, por meio deste reconhecimento, uma nova realidade, jurídica, política, administrativa e mesmo social. Enfim, qual o modelo normativo que derivará do reconhecimento desta grande variedade de situações empíricas ou que será imposto a elas.

Falar de quilombos e dos quilombolas significa tratar de uma luta política em construção (LEITE, 2003). Diversas foram os autores que se dedicaram a conceituar teoricamente os quilombos, a exemplo de Moura (2014), Guimarães (1983), Gomes (1996), Schwartz (1994), Röhring-Assunção (1996), Leite (2003, 2005), dentre outros. De acordo com Marques (2009), os estudos sobre quilombos podem ser agrupados nas seguintes correntes: a) político-marcista; b) tecnicista; c) ressemantização. Esta última corrente busca superar o binômio fuga-resistência nos estudos sobre esses grupos. A ressemantização possibilita aos quilombolas "uma efetiva participação na vida política e pública, como sujeitos de direito. Além disso, a referida ressignificação afirma a diversidade histórica e a especificidade de cada grupo" (MARQUES, 2009, p.345).

Almeida (2002) nos ajuda a compreender que foram diversos os processos pelos quais os quilombolas ou remanescentes de quilombos foram se constituindo como grupo, com peculiaridades regionais e históricas. A luta pela posse da terra, por exemplo, nem sempre está presente em todas as comunidades quilombolas. A identidade quilombola está, assim relacionada a relação desses grupos com o território; relação direta com a ancestralidade, a cultura e as tradições; o uso comum da terra, tendo a unidade familiar como elemento essencial, como afirmação étnica e política (ALMEIDA, 2002).

As comunidades quilombolas vêm sendo objeto de estudos, nos últimos anos, em diferentes campos, a exemplo da Sociologia, Antropologia, Educação, Linguística, Genética, Saúde Coletiva, História conforme demonstra levantamento por nós efetuado na Biblioteca Digital de Teses e Dissertações (BDTD). Com os descritores quilombo/comunidade quilombola foram localizados 1470 trabalhos, destacando-se quantitativamente os estudos sobre a comunidade quilombola Kalunga, localizada no norte do Estado de Goiás, com 112 pesquisas.

As instituições com maior número de pesquisas sobre a temática são Universidade de Brasília (UNB), Universidade Federal de São Carlos (UFSCAR) e Universidade de São Paulo. Das pesquisas localizadas na BDTD, a maior parte foi realizada em programas de pósgraduação na área de Educação, destacando-se as seguintes temáticas de pesquisa: políticas públicas, identidade, práticas pedagógicas. Esse dado aponta para o fato de que a Educação tem se constituído como campo favorável à realização de pesquisas que procuram conhecer e desvelar diferentes elementos presentes na história e no cotidiano das comunidades quilombolas.

Oficialmente essas comunidades são definidas pela Secretaria de Políticas de Promoção 
da Igualdade Racial (SEPPIR) como:

grupos com trajetória histórica própria, cuja origem se refere a diferentes situações, a exemplo de doações de terras realizadas a partir da desagregação de monoculturas; compra de terras pelos próprios sujeitos, com o fim do sistema escravista; terras obtidas em troca da prestação de serviços; ou áreas ocupadas no processo de resistência ao sistema escravista" (BRASIL, 2015, s/p).

É na Constituição Cidadã de 1988 que o termo quilombola é incorporado, depois de muitas lutas, ao artigo 68 do Ato das Disposições Constitucionais Transitórias (ADCT), conferindo direitos aos remanescentes de comunidades de quilombo. No entanto, esse instrumento jurídico a partir de então foi motivo de embates e debates, pois conferia direitos a sujeitos até então abandonados e invisibilizados historicamente pelo Estado.

Do ponto de vista das políticas públicas para as comunidades quilombolas, no primeiro governo do ex-presidente Luiz Inácio Lula da Silva foi lançado, em 2004, o Programa Brasil Quilombola, momento em que finalmente a União definia marcos para as políticas estatais para os quilombos. Em 2007, por meio do Decreto 6261, as ações e políticas para esse grupo étnico foram agrupadas em quatro eixos: acesso à terra, infraestrutura e qualidade de vida, inclusão produtiva e desenvolvimento local, direitos e cidadania.

No âmbito da educação, em 2012 foram aprovadas as Diretrizes Curriculares Nacionais para a Educação Escolar Quilombola, instrumento importante para que as comunidades quilombolas insiram no currículo a cultura, a memória e a tradição das comunidades negras brasileiras.

Segundo informações da Fundação Cultural Palmares, até 31/08/2017 já tínhamos mais de 3.000 comunidades quilombolas certificadas no país, sendo que os Estados da Bahia (743), Maranhão (689), Minas Gerais (313), Pará (254), Pernambuco (153) e Rio Grande do Sul (127) são os que possuem maior número de comunidades nessa situação. A certificação, no entanto, não garante a posse da terra, de acordo com o INCRA, órgão responsável pela titulação das comunidades.

Neste artigo pontuamos alguns elementos teórico-conceituais que nos auxiliam a compreender os quilombolas, por nós compreendido como um grupo étnico. É um texto bibliográfico que pretende contribuir com a compreensão das atuais discussões acerca das comunidades quilombolas. Inicialmente abordamos o processo de produção da etnicidade. $\mathrm{Na}$ sequencia, apresentamos conceitos teóricos que nos permitem tomar os quilombolas enquanto grupo étnico.

\section{OS QUILOMBOLAS E A PRODUÇÃO DA ETNICIDADE}

Desde o início da diáspora negra, partindo da África rumo à costa atlântica, o negro conviveu com as mais humilhantes situações, seja de inferioridade, de tratamento enquanto mercadoria, de invisibilidade e/ou tratado como animal nas lavouras, deixando para trás toda uma vida e sua própria história. A forma com que os africanos foram trazidos para o Brasil arrancados de sua terra constitui um dos crimes mais cruéis cometidos na história da 
humanidade.

No contexto brasileiro de lutas por parte da população negra, no que diz respeito à visibilidade, o Estado sempre negligenciou o tratamento e o acesso dos negros a direitos essenciais, como educação e inclusão social até os anos 1980. Do ponto de vista legal, é com a Constituição de 1988 que a possibilidade de políticas estatais focalizadas tornou-se realidade.

O Estado brasileiro, valendo-se da narrativa oficial, historicamente desconsiderou os grupos não hegemônicos, principalmente mulheres e homens negras/os, que permanentemente foram representados através de identidades negativas, coisificados, tidos como escravos, seres sem história, sem cultura, sem vontade política e nem subjetividade. Conforme nos assinalam Melo et. al ( 2011, p.268):

A desconsideração dessas demandas por parte do Estado brasileiro compromete sobremaneira o próprio caráter democrático do sistema político do país, tendo em vista se tratarem de segmentos sociais que historicamente foram alijados de uma inserção político-social plena, justamente por serem portadores de lógicas culturais ou até mesmo fenótipos diferenciados dos modelos hegemônicos.

Zubaran e Silva (2012) apontam que a política de branqueamento foi implantada pela elite brasileira, após o fim do regime escravista, promovendo não apenas a migração europeia, mas um projeto de Estado. A ideia de paraíso racial vigorou por muito tempo entre nós. Candau (2003, p.1) afirma que:

A crença em uma democracia racial construiu no imaginário da população o mito de uma sociedade harmoniosa, não preconceituosa, que não se reconhece como racista e discriminadora. Enfim, um Brasil que seria um paraíso de raças. O desafio que se coloca, neste sentido, é continuar trabalhando para desvelar esse mito. Algo que supõe o reconhecimento da diferença como um dos elementos fundamentais de uma sociedade democrática e a afirmação da diversidade e pluralidade culturais, requerendo também a eliminação de estereótipos raciais e da visão de racismo cordial.

O mito da democracia racial por muito tempo serviu para a omissão, por parte do Estado, da implementação de políticas públicas direcionadas para a população negra e implantou no imaginário coletivo brasileiro um discurso de igualdade que se reatualiza constantemente, por mais que numerosas pesquisas evidenciem o quanto as desigualdades sociais produzem desigualdades raciais. Toniosso (2011, p.38) sinaliza que:

As profundas desigualdades de oportunidades a que estava submetida à população afrodescendente no Brasil e explicitam a falácia da democracia racial existente nos diversos níveis do sistema educacional. Essa constatação está em consonância com as históricas reivindicações do Movimento Negro, que influenciaram a aprovação de uma série de mudanças na legislação educacional, incluindo a lei $n^{\circ} 10.639 / 03$.

O mito da democracia racial serviu de aparato para homogeneizar o povo brasileiro, anular as desigualdades e diferenças. Quando voltamos nosso olhar para as comunidades 
negras rurais, percebemos que durante um século após a emancipação dos escravizados, os quilombos ficaram ausentes das políticas públicas implementadas pelo Estado.

Flávio Gomes (2015) afirma que os registros encontrados sobre os quilombos brasileiros foram produzidos por pessoas encarregadas de destruí-los, dessa forma esses escritos eram forjados de forma a reforçar a visão transgressora dos fugitivos. Para esse autor, os mocambos/quilombos não eram isolados geograficamente, conforme abordam as visões tradicionais. Muito ao contrário, havia uma rede de cooperação muito bem articulada entre os quilombos, a senzala, a casa grande e os comerciantes locais. Articulação essa que protegia os refugiados, pois muito antes das expedições repressoras chegarem, os mesmos já eram avisados por antecipação.

Qual era a base econômica quilombola? O melhor seria falar em múltiplas estruturas socioeconômicas, pois fatores geográficos, demográficos e culturais interferiram na montagem dela. O mais importante - em qualquer período ou local - foi o não isolamento. Houve quem dissesse que os quilombos/mocambos se isolaram do restante da sociedade e que tal isolamento - via de proteção - foi fundamental para sua reprodução[...]. No Brasil - ao contrário de outras áreas escravistas nas Américas -, as comunidades de fugitivos se proliferaram como em nenhum outro lugar, exatamente por sua capacidade de articulação com as lógicas econômicas das regiões onde se estabeleceram. (GOMES, 2015, p.19-20).

Flávio Gomes (2015) faz uma crítica às visões de quilombos produzidas no século XX, quais sejam a culturalista e a materialista. Enquanto a visão culturalista pensava os quilombos apenas como resistência cultural, a visão materialista concebia as comunidades como principal característica da resistência escrava aos maus tratos e à opressão senhorial. Essa segunda visão formulou intensas criticas às teses de Gilberto Freyre(1993) acerca da benevolência da escravidão brasileira.

Ki-Zerbo (2010) aponta que a oralidade foi um fator importante para os afrodescendentes conservarem suas tradições e conhecimentos. Além disso, formas outras de resistência sempre estiveram presentes (como as irmandades, os grupos negros) e auxiliaram também na preservação/manutenção da cultura e posterior organização enquanto movimento social.

Invisibilizados e impossibilitados de ascender socialmente, ao passo que abandonados por um Estado que fez questão de ignorá-las, as comunidades remanescentes de quilombos voltam a aparecer na Constituição de 1988, no artigo 68 do ADCT no seu capítulo 1. Nessa nova Constituição, aos remanescentes das comunidades de quilombos foram garantidos direitos. Arruti (2009, p. 66) aponta que:

A produção de novos sujeitos políticos, etnicamente diferenciados pelo termo "quilombola" tem inicio depois da ampla tomada de conhecimento dos novos direitos instituídos pelo "artigo 68" (Ato dos Dispositivos Constitucionais Transitórios / Constituição de 1988), que reconhece aos "remanescentes das comunidades de quilombo", a "propriedade definitiva" das terras "que estejam ocupando", assim como a obrigação do Estado em "emitir-lhes os títulos respectivos". 
A invisibilidade dos quilombos no Brasil foi efetivamente produzida por dispositivos jurídicos, aparatos midiáticos e discursos acadêmicos que consolidaram sua representação como fenômeno extinto e situado num passado de escravidão. No caso quilombola, podemos afirmar que "essa exclusão histórica passa também por um processo de negação baseado no esquecimento que legitimou a exclusão social a que essas populações foram relegadas" (FIAMENGUE \& WHITAKER, 2014, p.71).

No âmbito dos debates políticos, o artigo 68 do ADCT abriu uma ampla discussão interpretativa acerca do seu teor semântico, uma vez que pairava sobre ele uma ambiguidade interpretativa. Duas vias interpretativas se contrapunham na análise do dispositivo constitucional: uma primeira, dicionarizante, que tomava a noção histórica de quilombo para qualificar e reconhecer os quilombolas utilizando a literalidade do termo remanescentes de comunidades de quilombo para tornar o direito individual.

$\mathrm{Na}$ outra ponta dos debates, estava a busca por uma ressemantização do termo, tomando a escrita do artigo como comunidades remanescentes de quilombos. Assim, o direito não seria individual e, sim, coletivo. Essa vertente interpretativa contou com apoio da Associação Brasileira de Antropologia - ABA, que ancorada na teoria do norueguês Fredrik Barth (1969), na obra Os grupos étnicos e suas fronteiras, conseguiu trilhar um novo caminho para o reconhecimento por parte do Estado em relação às comunidades negras rurais.

Na perspectiva de Barth (1969), o que importa não são as diferenças ou classificações exógenas, mas sim as diferenças que os indivíduos consideram importantes e a elas atribuem significados; sua base está na autoatribuição categorial dos grupos étnicos.

Alicerçados na teoria de Barth (1969) em relação aos grupos étnicos e sob a luz do direito que André Videira de Figueiredo (2011) propõe, tomaremos os quilombolas como grupo étnico. Segundo Figueiredo (2011), a Ciência Jurídica, por meio da ressemantização, deixa de considerar o direito individual, como propõe a linha interpretativa tradicional e passa a ter o grupo étnico como o sujeito coletivo de direito.

É a partir do artigo 68 do ADCT, que a discussão acerca das comunidades negras rurais voltou ao centro das atenções, pois este dispositivo constitucional garante direitos a essas comunidades. No entanto, o maior entrave viria a ocorrer nos trâmites legais no que diz respeito às questões fundiárias, pois em sua maioria os remanescentes das comunidades quilombolas não tem mecanismos ou meios de comprovar a propriedade das terras ocupadas. Dois casos emblemáticos dessa situação foram a do Quilombo do Rio das Rãs, em Bom Jesus da Lapa - BA e a do Quilombo dos Macacos, em Simões Filhos - Bahia.

Conforme aponta Figueiredo (2011), o artigo 68 por si só não garantiria o direito às terras ocupadas, uma vez que na sua redação residiria uma ambiguidade semântica. Utilizando-se dessa ambivalência, os proprietários de terras alegavam que por ser "remanescentes de comunidades quilombolas" o direito era individual e não coletivo. É partindo dessa ambiguidade semântica que os antropólogos, estudiosos da área propõem a "ressemantização"do termo para "comunidades remanescentes dos quilombos" (ARRUTI, 2009; MELO, 2008; FIGUEIREDO, 2011).

Figueiredo (2011. p.18) sinaliza que: 
Considerando que o dispositivo constitucional não explicita os critérios para a definição do que seja "remanescente das comunidades de quilombos", ou para a definição das terras a que tais grupos têm direito, como operar sua aplicação? Se a princípio, a categoria remanescente de quilombo evocava o sentido de quilombo histórico de quilombo como comunidade de negros fugidos à época da escravidão, o processo de interpretação do dispositivo constitucional, por outro lado, não tardaria a operar a sua tradução para outra categoria, a de Comunidade negra rural, a partir da mediação do conceito antropológico de grupo étnico.

Nessa perspectiva, a ressemantização do artigo 68 buscou uma nova interpretação, abandonando a dicionarização do termo e a interpretação essencializada de visão interpretativa do dispositivo constitucional que reduzia o direito à esfera fundiária. Nessa visão tomava-se a concepção de quilombo histórico como critério de reconhecimento das comunidades remanescentes de quilombos.

Conforme Miranda (2016), remanescência não pode ser confundida com restos de um passado. É aquilo que não foi apagado, que não se pôde silenciar devido ao excesso de apego coletivo: cantos, costumes, formas de fazer o cotidiano, formas de transmitir e atualizar o que é ser quilombola.

Assim, na interpretação ressemantizada do artigo 68, o étnico se afirma no afastamento tanto do cultural quanto do racial e que a política a partir do étnico transitará entre o cultural e agrário, desembocando entre as demandas de reconhecimento e redistribuição, tendo em vista a ambiguidade das políticas institucionalizadas (FIGUEIREDO, 2011).

Sobre isso, o autor ainda assinala que:

Se a redação do artigo 68 partiu de um reconhecimento limitado dos grupos a serem atingidos pela norma constitucional, do que decorre uma discussão a apontar para o passado, para uma concepção histórica e arqueológica de quilombo, e não para uma concepção presencial relativa aos grupos sociais existentes. (FIGUEIREDO, 2011, p. 43).

Conforme Figueiredo (2011), reconhecimento e redistribuição estão interligados na definição dos contornos da política quilombola no Brasil, cuja natureza é hibrida: combina e confunde o étnico e o cultural.

No caso das comunidades quilombolas brasileiras, a política de reconhecimento encontra na obra do Alemão Axel Honneth (2003) "Luta por Reconhecimento", elementos que nos ajudam a compreendê-la. Segundo o autor, o princípio do reconhecimento jurídico das identidades coletivas constitui o resultado das lutas dos grupos sociais organizados a partir de uma experiência de desrespeito, sendo essa experiência o fator que desencadeia os conflitos sociais. A ausência dessa estrutura de reconhecimento, segundo Honneth, desencadeia o aviltamento do indivíduo e a deflagração dos desajustes e patologias sociais.

Conforme argumenta O'Dwyer (2013), assumir a identidade quilombola é estar disposto a carregar as marcas e os estigmas de um passado de escravidão, que se alimentou e reinventou até hoje. A autora enfatiza que ser quilombola envolve não só a titulação coletiva do território, como também estar inserido nas redes de relações próprias das comunidades, e também ter um modo de ser considerado distinto, que os define de dentro em rela- 
ção aos de fora.

Os elementos até aqui pontuados nos auxiliam na compreensão de como a etnicidade é produzida. De acordo com Banton (1977), a etnicidade pode ser definida como um sentimento, um discurso e uma tomada de posição política produzida pela positivação do estigma de raça. Sendo assim, Arruti $(2014 ; 2017)$ aponta que sendo um grupo distinto por características ditas raciais, tornar-se-ia um grupo étnico a partir do momento em que, aceitando a distinção que lhe é imposta pela maioria, passa a utilizar-se politicamente dela na formação de agrupamentos autônomos ou com interesses e reivindicações comuns. É exatamente isso que visualizamos com os quilombolas. Esses sujeitos, ao se organizarem, deram origem a novos movimentos sociais e passam a demandar seu reconhecimento enquanto grupo étnico.

É no conflito em torno dos limites entre o respeito e o desrespeito e a capacidade de agenciar positivamente na forma de comunidade imaginada os estigmas do passado, que se torna possível reimaginar a etnicidade: ela emerge na interação em contextos poliétnicos (ARRUTI, 2014). Conforme Honneth (2003), uma experiência de desrespeito pode, em contexto propicio, promover um conflito via movimento social. Seria então esse sentimento de solidariedade que uniria os indivíduos e nessa luta por reconhecimento esses sujeitos estariam produzindo etnicidade.

A positivação dos estigmas seria o próprio vínculo que liga os sujeitos entre si por meio das marcas. Assim, a etnicidade passa, nesse contexto, a descrever performances identitárias que incluem também os amplos contextos derivados da diáspora africana (ARRUTI, 2014).

\section{OS QUILOMBOLA COMO GRUPO ÉTNICO}

A teoria dos grupos étnicos formulada por Fredrik Barth (1969) foi de importância substancial no debate político das questões quilombolas no Brasil. A teoria Barthiana contribuiu para o reconhecimento dessas comunidades quando redireciona o foco do cultural para a autoatribuição categorial e dá relevância às diferenças que os sujeitos consideram significativas nas relações intergrupais.

A ênfase na etnicidade e na autoatribuição categorial concebida pelo autor norueguês contribuiu para superar as classificações naturalistas, históricas e culturalistas acerca dos grupos étnicos.

Segundo Barth (1969, p. 27), "Grupos étnicos são categorias atributivas e identificadoras empregadas pelos próprios atores, consequentemente, tem como características organizar as interações entre as pessoas". Assim, a conservação dos grupos étnicos não está no seu conteúdo cultural ou isolamento geográfico, mas sim na constituição e manutenção de suas fronteiras. $\mathrm{O}$ autor ainda aponta que:

Em primeiro lugar, torna-se claro que as fronteiras étnicas permanecem apesar dos fluxos de pessoas que as atravessam. Em outras palavras, as distinções entre categorias étnicas não dependem de ausência de mobilidade, contato e informação, mas implicam efetivamente processos de exclusão e de 
incorporação, através dos quais, apesar das mudanças de participação e pertencimento ao longo das histórias de vida individuais, essas distinções são mantidas. Em segundo lugar, há relações sociais estáveis, persistentes e frequentemente vitais que não apenas atravessam essas fronteiras como também muitas vezes baseiam-se precisamente na existência de status étnicos dicotomizados. (BARTH, 1969. p. 27)

Conforme descrito por Barth (1969), as fronteiras não são fixas e intransponíveis; o trânsito continuo se faz necessário para a consolidação da dicotomização entre os de dentro e os de fora, as fronteiras étnicas são reforçadas mediante a interação entre os diversos grupos étnicos contrapondo a tese do isolamento para manutenção dessas fronteiras. $\mathrm{O}$ autor aponta ainda que os grupos étnicos por serem categorias organizacionais, onde os símbolos adscritivos necessitam de atribuições dos indivíduos para obterem relevância.

Na medida em que os autores usam essas categorias para organizarem a si e aos outros, eles se configuram como grupos étnicos. Nesse contexto, a cultura só ganha importância na medida em que os indivíduos Ihes atribuem relevância, assim as categorias étnicas funcionam como recipiente organizacional capaz de receber diversas proporções e formas de conteúdo nos mais variados sistemas socioculturais (ARRUTI, 2014).

Ainda na esteira de Barth (1969), o grupo étnico não está baseado na ocupação de territórios exclusivos nem no isolamento,conforme dissemos anteriormente, mas na reafirmação contínua de sua diferença na relação e em relação aos outros. O autor afirma que a etnicidade é produzida de forma atitudinal e pode ultrapassar os limites organizacionais dos grupos étnicos.

Corroborando com Barth (1969), Arruti (2014, p. 208) afirma que:

A etnicidade seria um sentimento, um discurso e uma tomada de posição política produzida pela positivação do estigma da raça. Dessa forma, um grupo até então distinto por características ditas raciais, tornar-se-ia um grupo étnico a partir do momento em que, aceitando a distinção que lhe é imposta pela maioria, passa a utilizar-se politicamente dela na sua formação de agrupamentos autônomos ou com interesses e reivindicações comuns.

Partindo das assertivas propostas por Barth (1969) e Arruti (2014), nos ancorando na discussão de André Videira de Figueiredo (2011), buscamos uma articulação mediante a ambiguidade do artigo 68 das ADCT e a sua ressemantização pelos antropólogos, assentados na teoria barthiana e sob a luz do direito, discutir a questão quilombola no Brasil, afirmando que o direito coletivo das comunidades remanescentes de quilombos ganha força no âmbito político e jurídico quando esses (os quilombolas) são por autoatribuição tomados como grupo étnico.

Conforme abordado anteriormente, o artigo 68-ADCT da Constituição de 1988, devido à sua bivalência semântica, abriu um amplo espaço de debates e embates políticos. Nesse sentido, Figueiredo (2011) afirma que a abertura interpretativa, entretanto, teve por consequência a organização de um forte movimento de oposição às políticas quilombolas, tanto no campo político quanto na formação de opinião, articulando, na maioria das vezes, a multirracialidade brasileira. 
As interpretações feitas ao artigo 68 carregam em si uma gama de interesses, que na sua grande maioria desliza para as questões fundiárias: se por um lado a interpretação dicionarizante do dispositivo constitucional busca legitimar o direito dos remanescentes como individual, a ressemantização alicerçada na teoria barthiana e mediada pela Associação Brasileira de Antropologia - ABA, articulou uma interpretação em que o direito não seria individualizado, muito pelo contrário, ele seria coletivo.

Assim, Figueiredo (2011, p.26) assinala que:

As lutas em torno dos direitos das comunidades negras rurais são formuladas, via de regra, em um campo caracterizado pela liminaridade: por um lado, tais direitos são afirmados em torno da terra, entendida como meio de produção e reprodução dos grupos; por outro, trata-se do reconhecimento de uma identidade coletiva própria e particular, traduzida no campo jurídico-politico pelo termo remanescentes de quilombo, identidade racializada e historicamente referida.

Nesse espaço de disputas e inúmeras tentativas de individualizar o direito coletivo das comunidades remanescentes de quilombos é que tomaremos os quilombolas como grupo étnico, seguindo o pensamento de José Mauricio Arruti (2009, p.93), em que o autor aponta que:

O conceito de grupo étnico surge, então, associado à ideia de uma afirmação de identidade (quilombola) que rapidamente desliza sistematicamente para a adoção de auto-atribuição, seguindo o exemplo do tratamento legal dado à identidade indígena.

Na perspectiva dos estudos de Barth (1969), os grupos étnicos são categorias de atribuição e classificação feita pelos atores com a finalidade de organizar as interações. Articulando o conceito de Barth com o tratamento de Arruti, conferimos aos quilombolas a categoria de grupo étnico, que para se concretizar, necessita da autoatribuição.

Figueiredo (2011) afirma que a análise do caso das comunidades quilombolas no Brasil poderá descortinar novas dimensões das lutas e das políticas de reconhecimento, particularmente no que tange aos casos em que a afirmação dos direitos coletivos se dão em face às limitações dos interesses individuais. O autor enfatiza a importância da definição de quilombo como um grupo étnico com identidade autoatributiva, assim como a modalidade coletiva de apropriação da terra e a organização social baseada em laços de reciprocidade.

Nessa perspectiva, Eliane Cantarino O`Dwyer (2002; 2007) corrobora apontando que a multiplicidade de relações e significados que envolvem o cotidiano dos quilombolas autodesignados constitui espaços de sociabilidade orientados por estratégias de vida e destinos compartilhados como grupo étnico.

Assim como O`Dwyer (2014), Arruti (2009, 2017) e Figueiredo (2011) definem explicitamente que a definição de comunidade remanescente de quilombo como grupo étnico é combinada nas peças normativas de "terras de uso comum". Nesse sentido, Figueiredo (2011, p.42), sinaliza que: 
Ao contrário de outros grupos cujos direitos foram garantidos na Constituição de 1988, as comunidades quilombolas, entendidas aqui como grupos étnicos de ancestralidade negra com historicidade e territorialidade próprias, quaisquer que fossem os nomes pelos quais se chamavam ou eram chamadas, não haviam organizado suas demandas no plano nacional antes da Constituição de 1988.

Conforme Figueiredo (2011), a partir dos debates promovidos pela Associação Brasileira de Antropologia - ABA, que define que o sujeito de direito não é o remanescente individual, mas sim os "grupos étnicos de preponderância negra, encontráveis em todo o território nacional, identificáveis segundo categoria de autoatribuição habitualmente designados por terras de preto", os quilombolas passam a ser reconhecidos juridicamente como o sujeito coletivo de direito.

Almeida (2011) argumenta que o uso difuso da categoria quilombo, ressemantizada e tornada fator de mobilização política, reveste-se hoje de um significado de afirmação étnica, que transcende, entretanto, a ideia jurídica de reparo de injustiças históricas. Inscrevem-se, nesse processo, as práticas e ações sociais que visam garantir a terra como conjunto dos recursos naturais considerados imprescindíveis ao grupo.

Nessa perspectiva, o autor ainda sinaliza que os laços de solidariedade tornam-se convergentes a partir de mobilizações, seja de defesa do território e de confrontos face aos intrusamentos, seja em torno de afirmação identitária do grupo.

Ainda na perspectiva de Almeida (2011), a emergência do dado étnico aparece atrelada à consolidação de uma identidade coletiva fundada tanto numa autodefinição consensual, quanto em práticas político-organizativas, em sistemas produtivos intrínsecos e em símbolos próprios que podem, inclusive, evocar uma "ancestralidade" considerada legítima, mas que marca, sobretudo, uma política de diferenças face a outros grupos e uma relação conflitiva com as estruturas de poder do Estado, sobretudo com órgãos fundiários.

\section{CONSIDERAÇÕES FINAIS}

Neste artigo, pontuamos alguns elementos que nos ajudam a compreender e estudar as comunidades quilombolas. A teoria proposta por Barth em muito contribuiu com as discussões teóricas acerca dessas comunidades, conforme apontam pesquisas efetuadas em diferentes campos das ciências humanas.

A ressemantização trouxe diversas questões e impactaram diretamente as pesquisas acerca das comunidades quilombolas. Com o artigo 68 reconheceu legalmente a etnicidade já presentes nos estudos antropológicos. Uma das implicações desse reconhecimento foi a necessidade dos pesquisadores da temática compreenderem os quilombolas em suas diferentes matizes, concepções, metodologias, ideologias (MARQUES, 2009). Outra implicação diz respeito às questões que envolvem a relação entre Direito e Antropologia. O laudo antropológico passou a se constituir como documento fundamental nesse processo.

Outros trabalhos que visem aprofundar a teoria dos grupos étnicos, tanto do ponto de vista teórico quanto empírico, são fundamentais para cada vez mais visibilizarmos a memória, a cultura e as práticas sócio-históricas presentes no cotidiano das comunidades qui- 
lombolas.

Finalizamos destacando a necessidade da implementação de políticas públicas no campo educacional que considerem as demandas quilombolas, suas formas próprias de organização espacial, social e cultural, na perspectiva de uma educação diferenciada, conforme já previsto nas Diretrizes Curriculares Nacionais para a Educação Escolar Quilombola.

\section{REFERÊNCIAS}

ALMEIDA, Alfredo W. Berno de. Os Quilombos e as Novas Etnias. In: O'DWYER, Eliane Cantarino (org.). Quilombos: identidade étnica e territorialidade.. Rio de Janeiro: Editora FGV, 2002.

ALMEIDA, Alfredo Wagner Berno de. Quilombolas e novas etnias. Manaus: UEA Edições, 2011.

ARRUTI, José M. Conceitos, normas e números: uma introdução à educação escolar quilombola. Revista Contemporânea de Educação, vol. 12, n. 23, p.107-141, jan/abr de 2017. ARRUTI, José M. Quilombos. In: PINHO, Osmundo (org.). Raça: novas perspectivas antropológicas. 2. ed. Salvador: ABA/Ed. da Unicamp/EDUFBA, 2008.

ARRUTI, José M. Terras de Quilombo: identidade étnica e os caminhos do reconhecimento. Tomo, São Cristovão-SE. № 11, jul./dez. 2007.

. Etnicidade: In: SANSONE, Livio; FURTADO, Claúdio Alves (Orgs.). Dicionário crítico das ciências sociais dos países de fala oficial portuguesa. Salvador: EDUFBA, 2014.

. Mocambo: antropologia e história do processo de formação quilombola. Bauru, SP: EDUSC; São Paulo Associação Nacional de Pós-graduação e Pesquisa em Ciências Sociais, 2005.

BANTON, M. A ideia de raça. Lisboa: Edições 70, 1977.

BARTH, Fredrik. O Guru, o Iniciador e outras variações antropológicas. Rio de Janeiro: Contra Capa, 2000.

BRASIL. Diretrizes Curriculares Nacionais para a Educação Escolar Quilombola. Parecer CNE/CEB №. 16/2012. Brasília, Conselho Nacional de Educação, 2012.

CANDAU, Vera Maria. Somos tod@s iguais? Rio de Janeiro: DP\&A, 2003.

FIAMENGUE, Elis Cristina; WHITAKER, Dulce Consuelo Andreatta. Os desafios da emergência no Brasil de um rural "esquecido": as comunidades quilombolas. Retratos de Assentamentos, v. 17, n.1, 2014.

FIGUEIREDO, André Videira de. O caminho quilombola: sociologia jurídica do reconhecimento étnico. Curitiba: Appris, 2011.

GOMES, Flávio dos Santos. Mocambos e quilombos: uma história do campesinato negro no Brasil. São Paulo: Claro Enigma, 2015.

REIS, J. J.; GOMES, F. S. (orgs.). Liberdade por um fio: história dos quilombos no Brasil, São Paulo, Companhia das Letras, 1996.

GUIMARÃES, Carlos M. Uma negação da ordem escravista: Quilombos em Minas Gerais no século XVIII. Dissertação (Mestrado em História), Belo Horizonte, UFMG, 2003.

HONNETH, Axel. Luta por reconhecimento: a gramática moral dos conflitos sociais. Trad: 
Luis Repa. São Paulo: Ed.34, 2003.

KI-ZERBO, Joseph. História geral da África I: Metodologia e pré-história da África. 2. ed. rev. Brasília: UNESCO, 2010.

LEITE, Ilka B. O projeto político quilombola: desafios, conquistas e impasses atuais. Revista Estudos Feministas, v. 16, n. 3, p. 965-977, 2008.

LEITE, Ilka B. Os Quilombos no Brasil: questões conceituais e normativas. Florianopolis: NEAD, 2003. Disponível em http://www.nead.org.br/index.php?acao=artigo\&id=21.

MARQUES, Carlos E. De Quilombos a quilombolas: notas sobre um processo históricoetnográfico. Revista de Antropologia USP, vol.52, n.1, p.339-374.

MELLO, Marcelo Moura. Reminiscências dos Quilombos: território da memória em uma comunidade negra rural. São Paulo: Terceiro Nome, 2012.

MELO, Ana L.A. et al. "Palmas" para o quilombo: processos de territorialidade e etnicidade negra. Santa Maria: Ed. da UFSM, 2011.

MIRANDA, Shirley Aparecida de. Dilemas do reconhecimento: a escola quilombola "que vi de perto". Revista da ABPN, v. 8, n. 18, p. 68-89, Nov. 2015 - fev. 2016.

MOLINA, Mônica; FREITAS, H. C. de A. Avanços e desafios na construção da Educação do Campo. Revista Em Aberto, INEP, vol. 24, no 85, p.17-31, Brasília, 2011.

MOURA, Clovis. Rebeliões da senzala: quilombos, ressureições, guerrilhas. São Paulo: Anita Garibaldi, 2014.

O`DWYER, Eliane Cantarino. Processos identitários e a produção da etncidade. Rio de Janeiro: E-papers, 2013.

O'DWYER, Eliane Cantarino (org.). Quilombos: identidade étnica e territorialidade. Rio de Janeiro: FGV/ABA, 2002.

PRICE, Richard. Reinventando a história dos quilombos: rasuras e confabulações. Afro-Ásia, vol.23, p. 241-265,2000.

RÖHRIG-ASSUNÇÃO, Matthias .Quilombos Maranhenses. In: REIS, J. J.; GOMES, F. S. (orgs.). Liberdade por um fio: história dos quilombos no Brasil, São Paulo, Companhia das Letras, 1996.

SCHWARTZ, Stuart B. “Quilombos ou Mocambos. In: SILVA, M. B. N. da (org.). Dicionário da história da colonização portuguesa no Brasil. Lisboa: Verbo, 1994.

TONIOSSO, José P. Ensino de história e cultura afro- brasileira: da legislação à prática docente. Dissertação (Mestrado em Educação). Centro Universitário Moura Lacerda, Ribeirão Preto, 2011.

ZUBARAN, Maria Angélica; SILVA, Petronilha Beatriz Gonçalves. Interlocuções Sobre Estudos Afro-Brasileiros: Pertencimento étnico-racial, memórias negras e patrimônio cultural afro-brasileiro. Currículo sem Fronteiras, v.12, n.1, p. 130-140, 2012. 